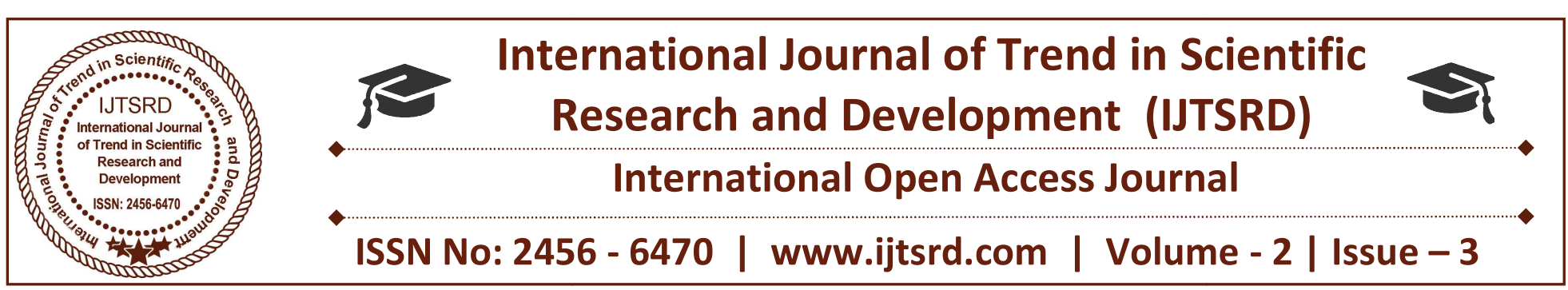

\title{
Simulation and Analysis of Variable Speed Wind Turbine Coupled With Self-Excited Induction Generator
}

\author{
S. Kannadhasan ${ }^{1}$, M. Saravanapandi ${ }^{2}$, C. Gurunathan ${ }^{3}$ \\ ${ }^{1,3}$ Lecturer, Department of Electrical and Electronics Engineering, \\ Tamilnadu Polytechnic College, Madurai, Tamil Nadu, India \\ ${ }^{2}$ Lecturer, Department of Electrical and Electronics Engineering, \\ Devangar Polytechnic College, Theni, Tamil Nadu, India
}

\section{ABSTRACT}

This paper presents the analysis of a wind driven Selfexcited induction generator [SEIG] is connected to the resistive load. The power flow analysis is carried out for different wind velocities. The proposed scheme for regulating the flow of power through rectifier ensures reduced reactive power burden on the self excitation capacitor bank. The induction generator wind turbine and the AC- DC converters are modeled using MAT LAB.

Keywords: Wind Turbine, Self Excitation Generator Model, Simulation, Matlab

\section{INTRODUCTION}

Wind electric power systems are recently gaining importance as they are cost competitive, environmentally clean and safe when compared to fossil fuel and nuclear power generation. Wind energy is one of the most important and promising sources of renewable energy all over the world. It has very large potential. Isolated wind energy conversion systems called as stand-alone systems are increasingly used in supplying power to remote areas. In these systems, self-excited induction generator are mainly used as they have some inherent advantages over conventional alternators in the aspect of reduced size, no DC supply for excitation, less maintenance cost, and better transient performance. When an induction machine is driven by a prime mover, the residual magnetism in the rotor produces a small voltage that causes a capacitive current to flow. The performance of a wind driven Self-Excited Induction Generator (SEIG) has been reported.

\section{SYSTEM CONFIGURATION}

The proposed scheme consists of a self-excited induction generator driven by a wind turbine and diode bridge rectifier to resistive load as shown in figure 1. The mathematical modeling of each component of the wind energy conversion system presented. The value of the capacitance is chosen to study the power quality effect in the three phase induction generator keeping the terminal voltage constant regardless of the power output. The minimum capacitance required for self excitation is calculated from the per phase equivalent circuit of induction motor through nodal analysis method. The horizontal axis wind turbine acts as a prime mover to drive the self-excited induction generator. The wind turbine is coupled to the generator shaft through a step-up gearbox so that the generator runs at a higher rotational speed in spite of the low speed of the wind turbine. 


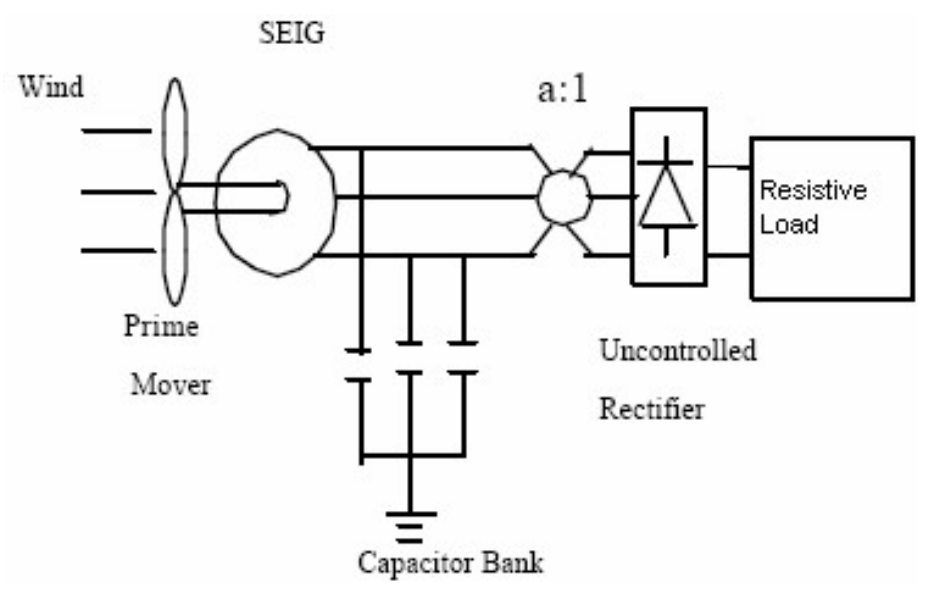

Fig.1.Block diagram of a Wind Energy Conversion System

\section{A. Wind Turbine Model}

Most of the wind turbine generators use horizontal axis wind turbine due to the advantages of easy in design and cheaper in cost for higher power ratings. The horizontal axis wind turbine acts as a prime mover to drive the self-excited induction generator is shown Fig.1 .The wind turbine is coupled to the generator shaft through a step-up gearbox. so that the generator runs at a higher rotational speed in spite of the low speed of the wind turbine. The wind turbine rotor consists of a hub, blades and blade extenders to increase the rotor diameter. The amount of power capable of being produced by a wind turbine $\left(\mathrm{P}_{\mathrm{T}}\right)$ is dependent on the power co-efficient $\left(\mathrm{C}_{\mathrm{p}}\right)$ for the given turbine operating conditions and is given by Eqn. 2.1.

$$
P_{T}=0.5 \rho A C_{p},(\lambda) V^{3}-(2.1)
$$

The tip speed ratio is defined as the ratio of the linear speed of the tip of blades to the rotational speed of wind turbine[2] and is given by Eqn. 2.2.

$$
\lambda=\frac{\omega T R}{V}
$$

The average torque $\mathrm{Tm}$ at the generator shaft is

$$
T_{m}=\frac{T_{T}}{\eta_{\text {gearbox }}}
$$

The torque developed by the wind turbine may be expressed as

$$
T_{T}=\frac{P_{T}}{\omega_{T}}
$$

The Wind turbine flow chart is shown in Fig.2. The proposed wind turbine simulation block has been developedusing the Eqn. $2.1-2.3$. The simulated results are in Fig 5. Based on the theory of fluid mechanics, it can be shown that $\mathrm{CP}$ reaches the maximum value of 0.593 , referred as the Betz limit. This limit defines the maximum energy that can be extracted from wind. The variation of wind turbine output power with rotational speed is presented in figure 3 for different wind velocities.

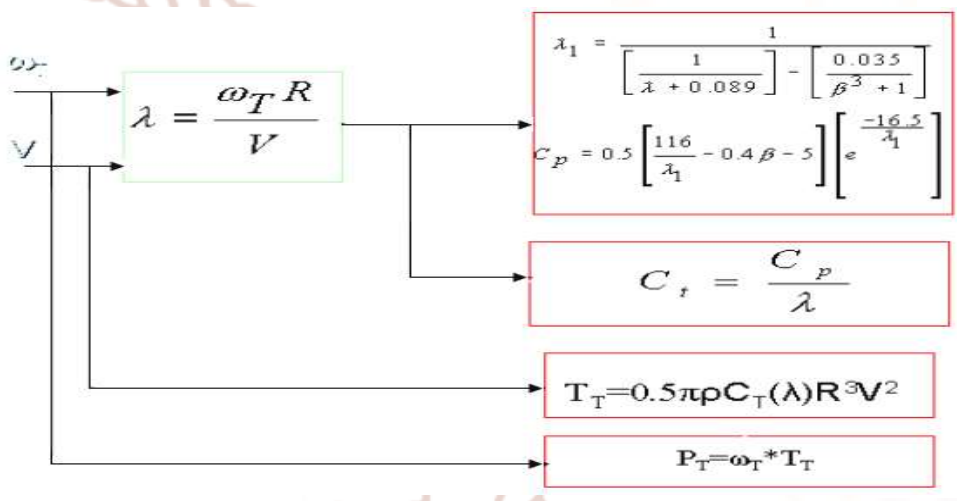

Fig.2. Flow chart of Wind Turbine

\section{B. Self-Excitation Induction Generator Model}

The $\mathrm{d}-\mathrm{q}$ axis model of an induction machine has been widely used; the model is usually adapted to analyze the machine performance under three phase balanced conditions. If the system is studied under an unbalanced three phase operating condition, the results obtained from the $\mathrm{d}-\mathrm{q}$ axis induction machine model will become very complicated, since a zero axis quantity corresponding to a zero sequence component will be generated.

The self-excited induction generator is essentially an induction machine driven by a prime mover with capacitor connected at the stator terminals as shown in Fig.1. the following assumptions are made in the simulation analysis

$>$ All parameters of the machine can be considered as constant except the magnetizing reactance $X_{m}$.

$>$ The leakage inductances of stator and rotor are taken to be equal.

Core loss in the excitation branch is neglected. 
The loop equations for the $\mathrm{d}$-axis and q-axis equivalent circuits are

$$
\begin{aligned}
& r_{s} i_{q s}+L_{s} \frac{d i_{q s}}{d t}+L_{m} \frac{d i_{q r}}{d t}=V_{d s} \omega_{e} \\
& r_{r} i_{q r}+L_{r} \frac{d i_{q r}}{d t}+L_{m} \frac{d i_{q s}}{d t}=V_{d r}\left(\omega_{e}-\omega_{r}\right) \\
& r_{s} i_{d s}+L_{s} \frac{d i_{d s}}{d t}+L_{m} \frac{d i_{d r}}{d t}=-V_{d s}+V_{q s} \omega_{e} \\
& r_{r} i_{d r}+L_{r} \frac{d i_{d r}}{d t}+L_{m} \frac{d i_{d s}}{d t}=V_{q r}\left(\omega_{e}-\omega_{r}\right)
\end{aligned}
$$

The dynamics of the self-excited induction generator can be represented by the following electromechanical equations derived in the synchronously rotating $\mathrm{q}-\mathrm{d}$ reference frame.

\section{Uncontrolled Bridge Rectifier}

In three-phase diode bridge rectifier is converts alternating current into direct current. The output DC voltage $\left(\mathrm{V}_{\mathrm{DC}}\right.$ of this rectifier can be expressed in terms of the generator's phase voltage $\left(\mathrm{V}_{\mathrm{T}}\right)$ and then transformation ratio $(\omega)$ as

$$
V_{D C}=\left(\frac{3 \sqrt{3}}{\pi}\right) *\left(\frac{\sqrt{2}}{a}\right) * V_{T}
$$

Assuming that the bridge rectifier is ideal, the power on the A.C side will equal the D.C power on the D.C sides, this yield

$$
3 V_{T} I_{L}=V_{D C} I_{D C}
$$

Substitute the Eqn.(2.15) in (2.14) given

$$
I_{D C}=\frac{\pi a}{\sqrt{6}} I_{L}
$$

\section{SIMULATION MODEL OF THE SEIG:}

The loop equations $2.4-2.7$ of $\mathrm{d}$-axis and q-axis equivalent circuit have to be developing the simulation model of SEIG. The SEIG characteristic equations are treated as a function, which might be written as MAT Lab. The simulation model of SEIG is shown in Fig.3. The simulated results are shown in Fig. 4 .

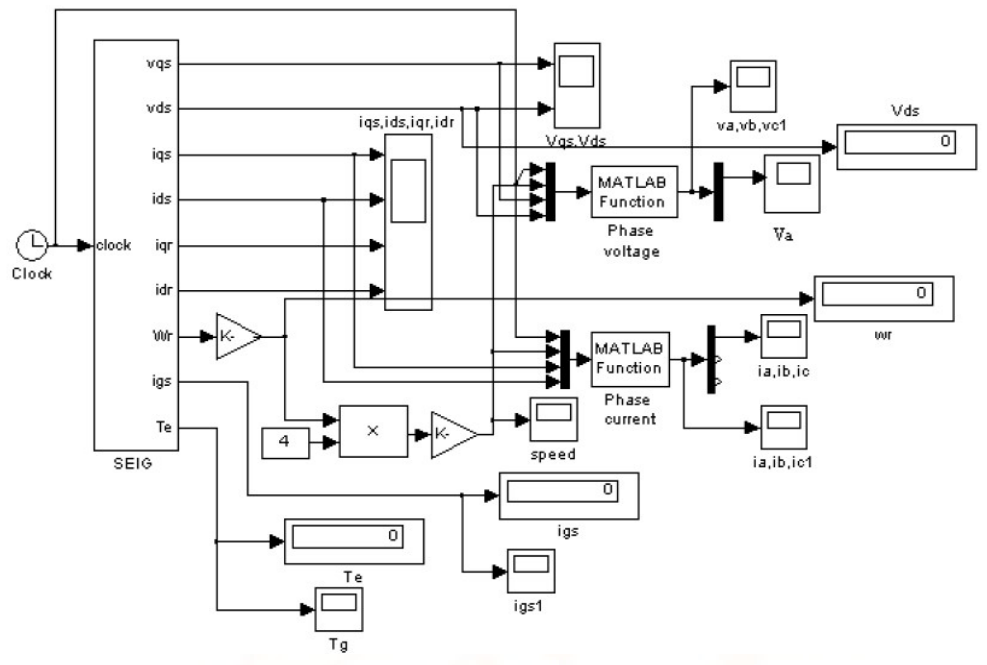

Fig. 3. Simulink Model of SEIG

\section{IV.RESULTS AND DISCUSSION}

The simulated and experimental results of a Selfexcited induction generator have been analyzed.

\section{A.Simulated Waveforms of Wind Turbine Characteristics}

The parameters of the $3.7 \mathrm{k} . \mathrm{w}$ wind turbine are given in appendix. The wind turbine is simulated in MatLab / Simulink. The variation of wind turbine torque and power with rotational speed is presented in Fig. 4 for different wind velocities.

\section{B. Simulation Results of the SEIG with out Rectifier:}

The proposed system configuration simulated results are shown in Fig 5 to 7. The performance of the SEIG such as torque, speed, voltage and generated current for step changes in load for a generator speed of 1520 $\mathrm{rpm}$ with rated capacitance $40 \mu \mathrm{F}$ at the stator terminals. Self-Excitation process is initiated at $\mathrm{t}=0 \mathrm{~s}$ without any load at the stator terminals. As the load on the generator increases, the stator voltage decreases with increases in the stator current.

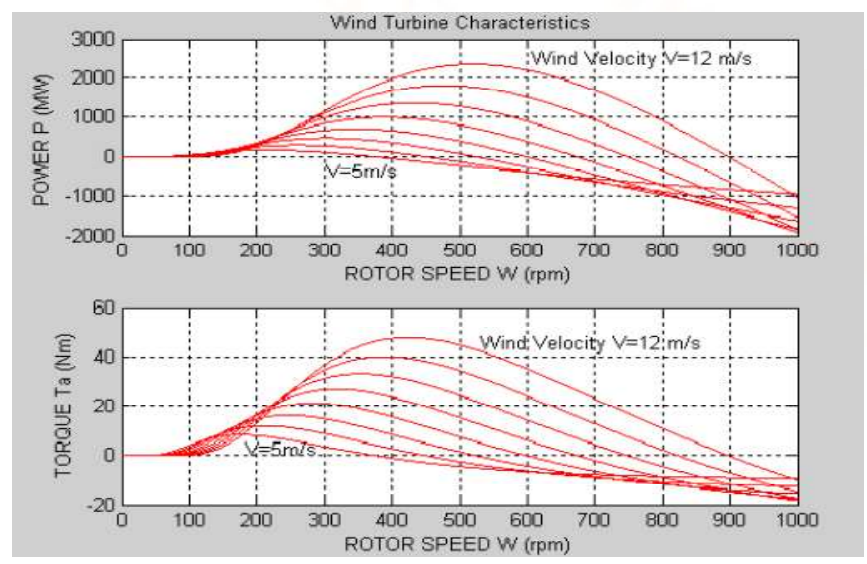

Fig.4. Wind Turbine Characteristics 


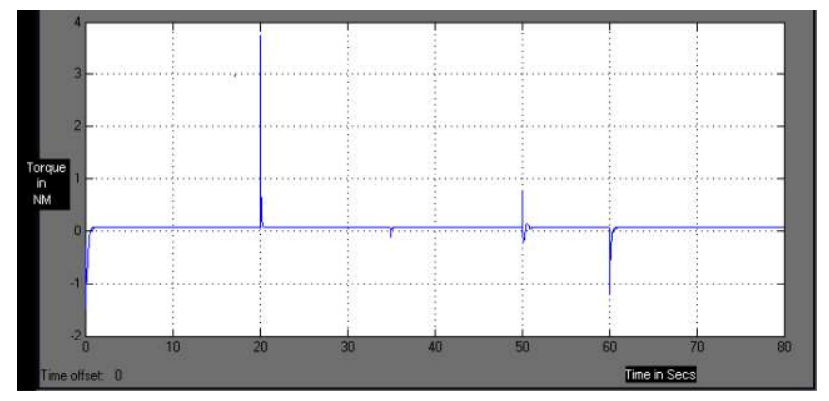

Fig.5.Generated Torque Vs Time characteristics of SEIG

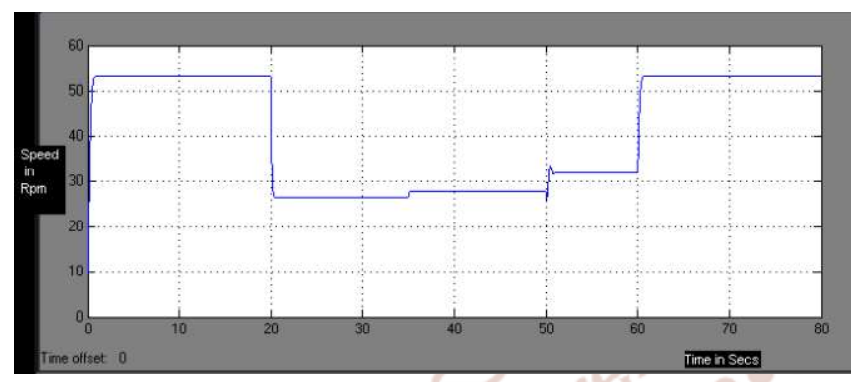

Fig.6. Speed Vs Time characteristics of SEIG

As the load on the generator increases, the stator voltage decreases with an increase in the stator current. At $\mathrm{t}=35$ secs, the capacitance is increased to $40 \mu \mathrm{f}$ to compensate for the voltage drop. The voltage rises to its no load value. All current, torque and output power increase. At $\mathrm{t}=50 \mathrm{secs}$, the capacitance is decreased to $9 \mu \mathrm{f}$. The generated voltage is decreased.

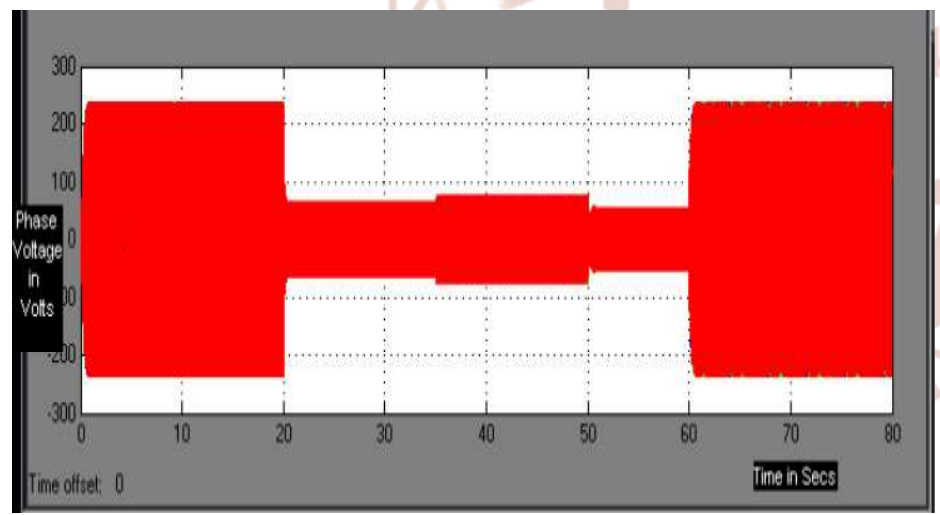

Fig.7. Generated Voltage Vs Characteristics of SEIG

\section{V.CONCLUSION}

A detailed performance analysis of a stand-alone wind energy conversion system fed resistive load has been studied. The SEIG output voltage is converted in to DC voltage by using un-controlled Diode bridge rectifier. This output voltage is controlled by the $\mathrm{R}$ load. It is observed that the generated voltage and frequency vary with wind velocity, capacitance and load. The simulation results have a good agreement with experimental result.

\section{REFERENCES}

1) Dawit $S$ Eyaum Colin Grantham, and Muhammed Fazlur Rahman,"The dynamic characteristics of an isolated self-excited induction generator driven by a wind turbine", IEEE, Transaction on Industry applications, Vol. 39.No.4 , July/August 2003 pp 936 - 944.

2) Alan Mullane, G. Lightbody, R. Yacamini, "Adaptive Control of Variable Speed Wind Turbines," IEEE Proceedings.

3) Yaser Anagreh "Steady state performance of series DC motor powered by wind driven selfexcited induction generator," Rev. Energ. Ren: power Engineering, 2001,pp 9-15.

4) Ali, A., Goldeb, S., Alama, F. and Moria, H., Experimental and Computational Study of a Micro Vertical Axis Wind Turbine, Procedia Engineering, 2012, 49:254-262

5) Park, J., Kim, J., Shin, Y., Lee, J. and Park, J., 3 MW Class Offshore Wind Turbine Development, Current Applied Physics, 2010, 10:307-310

6) Solero L., Caricchi F., Crescimbini F. and Falchetta M., Direct-Drive Wind Generator Pilot Plant for Stand-Alone Units in Extremely Cold Climates, Int J REE, 2001, 3(2):326-329

7) B. M. Nagai, B. M., Ameku K. and Roy J. N., Performance of A $3 \mathrm{~kW}$ Wind Turbine Generator with Variable Pitch Control System, Applied Energy, 2009, 86:1774-1782

8) L. Ledo, P. B. Kosasih and P. Cooper, Roof Mounting Site Analysis For Micro-Wind Turbines, Renewable Energy, 2011, 36:1379-1391

9) Y. F. Wang and M S. Zhan., 3- Dimentional CFD Simulation and Analysis on Performance of a Micro-Wind Turbine Resembling Lotus In Shape, Energy ang Buildings, 2013, 65:66-74

10) L. Santoli, A. Albo, D. A. Garcia, D. Bruschi and F. Cuma, A Preliminary Energy and Enviromental Assessment of a Micro Wind Turbine Prototype In Natural Protected Areas, Sustainable Energy Technologies and Assessments, 2014, 8:42-56

11) WWEA, World Wind Energy Association. 2012 Half year report. WWEA; 2012

12) EWEA, The European Wind Energy Association. A report by The European Wind Energy Association 2011. Belgium: EWEA; 2011

13) Gilbert, M. M., Renewable and Efficient Electric Power Systems, 2004, John Wiley \& Sons, USA 